Article

\title{
Card Stories on YouTube: A New Frame for Online Self-Disclosure
}

Sabina Misoch

Department of Sociology, University of Lucerne, Frohburgstrasse 3, 6002 Lucerne, Switzerland;

E-Mail: sabina.misoch@unilu.ch; Tel: +41 4122953 61; Fax: +41 412295335

\section{How to Cite this Article}

Misoch, S. (2014). Card Stories on YouTube: A New Frame for Online Self-Disclosure. Media and Communication, 2(1), 2-12.

\section{Copyrights}

(C) 2014 by the author; licensee Cogitatio (Lisbon, Portugal). This article is licensed under a Creative Commons Attribution 4.0 International License (CC BY).

\section{Published by:}

\section{COGITATIO}

www.cogitatiopress.com

\author{
About the Journal \\ Media and Communication is an international open access journal dedicated to a wide variety of basic and applied research in \\ communication and its related fields. It aims at providing a research forum on the social and cultural relevance of media and \\ communication processes. \\ www.cogitatiopress.com/mediaandcommunication \\ Editors-in-Chief \\ Professor Bradley Greenberg, Departments of Communication and Telecommunication, Information Studies and Media, \\ Michigan State University, USA \\ Professor Elisabeth Klaus, Department of Communication, University of Salzburg, Austria

\section{Managing Editor} \\ Mr. António Vieira, Media and Communication, Cogitatio Press, Portugal
}


Article

\title{
Card Stories on YouTube: A New Frame for Online Self-Disclosure
}

\author{
Sabina Misoch \\ Department of Sociology, University of Lucerne, Frohburgstrasse 3, 6002 Lucerne, Switzerland; \\ E-Mail: sabina.misoch@unilu.ch; Tel: +41-41-229-53-61; Fax: +41-41-229-53-35
}

Submitted: 8 August 2013 | In Revised Form: 30 January 2014 | Accepted: 18 February 2014 | Published: 9 April 2014

\begin{abstract}
This paper deals with the phenomenon of so-called (note) card stories on YouTube. Card stories can be described as selfdisclosing videos or confessions, using a new frame for telling one's own story audio-visually to the public by combining 'old' (hand-written messages) and 'new' media (video, computer mediated communication). In 2012/13, a qualitative and exploratory study with a sample of 25 card story videos on YouTube was conducted. The content and visual analysis revealed (1) that these videos are bound to a very specific frame of presentation, (2) that they deal with specific topics, and (3) that the presenter does not remain (visually) anonymous. These findings question previous research results that stressed a strong correlation between online self-disclosure and (visual) anonymity; further, the findings show that this special frame of textual confessions via video supports deep self-disclosures.
\end{abstract}

\section{Keywords}

anonymity; card story; computer-mediated communication; frame; self-disclosure; video; YouTube

Issue

This article is part of a regular issue of Media and Communication, edited by Professor Bradley Greenberg (Michigan State University, USA) and Professor Elisabeth Klaus (University of Salzburg, Austria).

(C) 2014 by the author; licensee Cogitatio (Lisbon, Portugal). This article is licensed under a Creative Commons Attribution 4.0 International License (CC BY).

\section{1. (Note) Card Stories on YouTube}

YouTube is a video-sharing website that was founded in 2005. By November 2007, it was already the most popular entertainment website in Britain (Burgess \& Green, 2009) and was bought by Google in 2006 for 1.65 billion USD (Google Blogspot, n.d.).

It is a social-network oriented video platform (Lange, 2007), allowing its users to watch or to upload videos, to share content, to subscribe to channels, to comment or to rate videos. At the beginning, YouTube's slogan 'Your Digital Video Repository' soon changed to 'broadcast yourself'. 'This shift from the idea of the website as a personal storage facility for video content to a platform for public self-expression matches YouTube to the ideas about a user-led revolution that characterizes rhetoric around Web 2.0' (Burgess \& Green, 2009). In the meantime, it has become the largest user-generated content video system worldwide (Cha, Kwak, Rodriguez, Ahn \& Moon, 2007) and one of the fastest growing and mostused websites. This platform allows the users to 'move seamlessly between traditional mass communication activity of watching mediated content, and interpersonal or social connection activity of sharing it with others' (Haridakis \& Hanson, 2009). The videos uploaded on YouTube are divided into different categories: sports, music, entertainment, film, comedy, gaming, and vlogsjust to mention a few. As studies have shown, usergenerated content does not seem to be as present as presumed (Kruitbosch \& Nack, 2008). Concerning YouTube, we find professional produced and usergenerated content.

One part of the user-generated content is the socalled videoblogs (vlogs). Videoblogs can be defined as 'sites where authors post stories and/or information about themselves in the form of video, rather than text, as traditional blogs include. They are public spaces for self-expression where authors control the content published' (Griffith \& Papacharissi, 2010). In these videoblogs, the producers present themselves to the public on YouTube-these media products serve one's self-presentation. 
The term 'story' (instead of history) used in 'note card story' implies the subjective, narrative description of the presented content; a history would be the objective narration of past events. One of the first and most famous videos of this genre was the video by Jonah Mowry: 'Whats goin on...' uploaded on August 10, 2011 (since then, it has more than 10 million views). The producer of this video talks and writes about his experience with and suffering from mobbing, self-injury, depression, and feelings of loneliness. This visual self-disclosure in the form of a written public confession was followed by numerous other videos using this new frame to reveal very private and intimate information (e.g., mobbing, death of a friend/relative, sexuality (lesbian, gay), depression, eating disorders, self-injury, loneliness, and suicidal thoughts). One of the best-known note card stories was published by 15 -year-old Amanda Todd: she disclosed her story about being a bullying victim, having depression, and injuring herself on YouTube. The video was watched more than 1.6 million times within the first week of its online publication. She killed herself in October 2012. Her case generated a groundswell of public anger.

Note card stories are a phenomenon, increasing tremendously within the last year. When the sampling for this study was conducted, 6500 results were found (in December 2012) by using the search term 'note card story'. New research in September 2013 revealed more than 3 million results. This enormously increased number of results illustrates how common the phenomenon of note card stories has become on YouTube (taking into account that not all results are note card stories as defined).

\section{Theoretical Frame}

\subsection{Self-Disclosure}

\subsubsection{In General}

'Talking about our private feelings in public is not always easy' (Petronio, 2002). This statement draws attention to the problems of self-disclosure, which describes the situation where individuals reveal personal and therefore often private and sensitive information to others (Archer, 1980). This process necessarily does not need to be public, and it is an essential precondition that the information disclosed is confidential. Self-disclosure can be differentiated with regard to the truthfulness of the content (Barbour, 2001), and only in the case of truthfulness can we call these phenomena self-disclosures (Misoch, 2013). To reveal information can be conceptualized as a voluntary process (Pearce \& Sharp, 1973) when one person tells another person 'things about himself, which the other is unlikely to know or to discover from other sources' (Pearce \& Sharp, 1973). Within the act of disclosing, individuals tell others things about themselves, which the others otherwise would not know, and through this pro- cess, the individuals make themselves vulnerable because there 'are risks that include making private disclosures to the wrong people, disclosing at a bad time, telling too much about ourselves, or compromising others' (Petronio, 2002).

Self-disclosure only concerns one's own information. It varies in breadth (or amount), intimacy (or depth), and duration (Cozby, 1973). Breadth means the number of details that are revealed; intimacy describes the level of privacy, and duration the time spent on revealing information. In addition to these differentiations, we can distinguish between voluntary and involuntary disclosure of self-related information (Attrill, 2012).

Self-disclosure is a process, normally occurring during social interactions and is important for the development and strengthening of interpersonal relationships (e.g., Derlega, Metts, Petronio \& Margulis, 1993). Researchers assume that this phenomenon occurs when relationships develop from not intimate to more and more intimate information exchange (social penetration theory, Altman \& Taylor, 1973). Therefore, it is usually a process that occurs incrementally and takes time (e.g., Pearce \& Sharp, 1973 , summary). There is a lot of research on the relationship between self-disclosure and liking (Berg \& Archer, 1983; Chaikin \& Derlega, 1974), perceptions of selfdisclosures (Kleinke \& Kahn, 1980), or its relationship to trust (Wheeless \& Grotz, 1977; Vondracek \& Marshall, 1971). Self-disclosure is presumed to be a symmetrical process within dyads (e.g., Jourard \& Landsman, 1960; Jourard \& Resnick, 1970), and is normally characterized by reciprocity (Jourard \& Landsman, 1960; Jourard, 1959; Jourard, 1963). Relating to Uncertainty Reduction Theory (URT) (Berger \& Calabrese, 1975), people use interpersonal communication to reduce uncertainty. In initial interactions, people are driven by the desire to reduce uncertainty and use active, passive, and interactive strategies to serve this goal. Disclosing personal information is one of the key variables within this process and can be described as an active strategy to reduce uncertainty.

This paper focuses on the frame of note card stories, which enhances processes of self-disclosure. To serve this goal, qualitative data is used to develop hypotheses concerning the relationship between visual cues and the willingness to voluntarily disclose information online and furthermore to provide a deep description of the frame of audio-visual 'note card stories'.

\subsubsection{Online Self-Disclosure}

Regarding the phenomenon of self-disclosure against the background of digitalization and computer-mediated communication, the results of previous studies have shown a clear tendency to the conclusion that the willingness to self-disclose information is significantly higher in the context of computer-mediated communication compared to face-to-face-settings (e.g., Weisband \& Kiesler, 1996; Joinson, 2001; Misoch, 2012; Misoch, 2014). 
Recent research concerning the willingness to disclose information online has revealed three main factors:

1. (Visual) anonymity: A relation between the anonymity (in the sense that users are not identifiable) and the users' willingness to self-disclose information online could empirically be shown (Joinson, 2001). This effect seems not to be restricted to online communication because it can also be shown in real life, e.g., when confessing or talking to a crisis line. As Joinson has shown, visual anonymity seems to play a decisive role for this process (Joinson, 2001). Recent studies have shown, however, a differentiated tendency that implies that the factor of visual anonymity seems to be overestimated. These studies (Misoch, 2014) revealed a clear tendency that there are online self-disclosures that are published and are deliberately not anonymous. This is particularly true regarding audio-visual self-disclosures on YouTube, which are subject to special framing conditions (Misoch, 2014).

2. Social presence: Social presence is generally defined as 'the degree of salience of the other person in the interaction' and is conceptualized as the 'subjective characteristic of the medium' (Short, Williams \& Christie, 1976), measured by subjective ratings. These ratings are based on the feelings of presence, which seem to be related to the number of channels provided by the medium (Short, Williams \& Christie, 1976). Following this concept, the ideal type of communication is the face-to-faceinteraction with visual perceptibility of all the actors. Therefore, the higher the sensual observable quotient, the higher the degree of social presence. If we adopt this concept to computer-mediated communication, it can be assumed that online (textual) communication has a very low degree of social presence. If we also define social presence as the 'sense of being with another' (Biocca, Harms \& Burgoon, 2003) and mutual awareness (Heeter, 1992), we can conclude that this degree is low when it comes to CMC. This has behavioural effects to the users; for example, that others are not felt as socially present, and this lack of social inclusion or social interaction leads to a user's enhanced self-reference, and within this possibly also to a user's heightened willingness to self-disclose information.

3. Private self-awareness: An individual can draw his or her attention either outwards or inwards to him- or herself (Duval \& Wicklund, 1972). If the attention is drawn inwards, one usually distinguishes between private and public self-awareness. Private self-awareness involves confidential and intimate aspects that are usually not shown (or not likely to be shown) in social contexts: '[...] private self consciousness [...] was concerned with attending to one's inner thoughts and feelings [...]' (Fenigstein, Scheier \& Buss, 1975). In contrast, public self-awareness involves those aspects that are openly presented in social contexts and outline parts of a social identity. Indeed, several studies have shown that computer-mediated communication (CMC) raises private self-awareness, among other things, through the user's physical isolation in front of the screen, and furthermore, lowers one's public self-awareness (Matheson \& Zanna, 1988). Other studies report that conditions of CMC lead to a highly reflective experience (Matheson, 1992). This experience of heightened private self-awareness seems to be related to anonymity (e.g., Kiesler, Siegel \& McGuire, 1984). Researchers found out that in reciprocal situations, a heightened private self-awareness is associated with an increased salience of one's own feelings (Scheier, 1976). This leads to an increased focus on oneself, which is the basis for processes of self-disclosure. Thus, self-disclosure is the result of self-focusing and orientation on one's standards and needs. Research has shown that a heightened self-awareness leads to more detailed and precise self-reports (concerning psychiatric patients), and decreases the influence of social norms and standards in the sense of social desirability (Joinson, 1999).

\subsection{The Concept of Framing}

A helpful tool for analysing card stories is the theory of framing, even though frame and frame analysis are neither a clear theoretical paradigm nor a specified methodological approach.

The genuine concept by Goffman (1974), which was inspired by Bateson (1973), states: 'I assume that definitions of a situation are built up in accordance with principles of organization which govern events [...] and our subjective involvement in them; frame is the word I use to refer to such of these basic elements as I am able to identify' (Goffman, 1974). In Goffman's view, a frame is a basic cognitive structure that guides our perception and interpretation of reality. Even though frames are not only consciously produced, Goffman differentiates between naturalistic and social frames. A correctly perceived frame helps individuals act within the scope of a specific frame.

Today, the concept of framing is applied to mass media and therefore means a cognitive frame that influences the audience's perception of reality. This new concept of framing in media studies - very different from the more sociological framing concept of Goffman - is based on the assumption that the perception of the audience can be influenced by the manner of information presentation and that the key elements are selection and salience (Entman, 1993; Fiske \& Taylor, 1991).

The concept of framing which is used in this paper is that developed by Goffman, which has already been successfully used to analyse YouTube videos (e.g., Lindgren, 2012). In keeping with Goffman's definition, framing is used in a broader understanding as a cognitive concept that is related to the premise: 'The picture frame tells the viewer that he is not to use the same sort of thinking in interpreting the picture that he might use in interpreting the wallpaper outside the frame' (Bateson, 2006). In this understanding, a frame routes the mental and cognitive 
understanding of a phenomenon. From this perspective, framing is a concept on a meta-communicative level and 'gives the receiver instructions or aids in his attempt to understand the messages included within the frame' (Bateson, 2006): a frame influences the recipient's expectations regarding the content and its way of interpretation. Thus, the model of framing describes a set of concepts and perspectives that influence the perception of the individual and the organisation of society. In this paper, we refer to this definition by Bateson and Goffman and therefore understand a frame as a structure of expectation.

\section{Empirical Investigation}

We regard note card stories as a special sub-type of vlogs: these videos do not serve purposes of 'classical' selfpresentation; rather, they conduce confessions. The emergence of this new frame for audio-visual disclosures on YouTube can be dated to 2009 because the 'oldest' videos we found were uploaded in 2009 (for example the following video response: https://www.youtube.com/ watch?v=DfUB55s41_Y, accessed on 24 November 2012).

These audio-visual stories in note form-mostly confessions-are the main focus of this paper and the core element of the empirical investigation. In order to analyse self-disclosures, the topics of the videos, their framing structure, and the degree of anonymity in card stories, we carried out an empirical study in 2012/13. This qualitative and exploratory study consisted of a sampling of 25 videos. Qualitative methods were used because the field of research is new and there is no pre-existing data. The sample was selected by using a hybrid (Barbour, 2001) of random and purposive sampling strategies. The sampling was carried out by using search terms like 'my story' or 'my note card story', and we used a list with random numbers (principle of contingency) to find the results. These in turn were checked according to the representational nature of the content and, when appropriate, added to the sample. Videos that used the frame of a card story for irony or parody were removed from the sample. The sampling itself was carried out in December 2012 and January 2013. A content analysis (Mayring, 2010) of the videos was carried out, and the final sample was analysed with regard to its topic, the inner (narrative) structure, and the degree of visual anonymity within the selfdisclosing videos. The content analysis of the visual and textual material was carried out. The focus of this analysis was to analyse the topics of these videos and the degree of anonymity to finally enable a close description of this new frame. This study was conducted as an exploratory study because there has not been any research until now concerning this new phenomenon, and we would like to gain a deeper understanding of note card stories.

Ethical considerations: The current analysis focuses on videos, in which people disclose private information about themselves to the public on YouTube, often without re- maining visually anonymous. Because the producers of note card stories publish their videos on YouTube, accessible to everyone with Internet access, we decided to publish screen shots of selected examples to better illustrate this new phenomenon of online self-disclosure, taking into account that the range of a research paper in a journal is not as large as the range of a digital video published on the Internet.

\section{Results}

Our sample consisted of 25 selected videos that were selected randomly and according to content validity; 17 produced by women, 6 by men and 2 by transgender/ transsexual users, which the latter assigned themselves to both sexes.

\subsection{Frame Analysis of Note Card Stories}

As described in Section 2.2, we refer to the framing concept developed by Bateson and Goffman. Frames are, in this understanding, structures that guide the perception and function as structures of expectation.

If we adopt this definition to our field of investigation, we can show that (note) card stories follow a quite narrow frame because they are all composed in a very similar manner. The length of the videos varies within our sample between 2:20 $\mathrm{min}$ and $8: 16 \mathrm{~min}$; the mean value is $5: 18$ $\min$.

(Note) card stories can be defined by the following characteristics, which are a combination of characteristics of video-communication and special attributes that only occur in note card story videos (see also Misoch, 2014):

1. Classical video characteristics on YouTube:

a. The video consists of auditory and visual elements;

b. A certain kind of stage acting, as the user produces a media product by him-/herself and uploads this medium for the public;

c. Unidirectional situation (presenter is sending his story to the public);

d. Social interaction is subordinated because it can only develop afterwards;

e. No symmetrical or reciprocal situation;

f. Unknown and dispersed public.

2. Special characteristics of note card stories on YouTube:

a. The presenter does not speak within this video (no verbal level);

b. The auditory elements are background music;

c. The message is conveyed visually to the public;

d. The notes are handwritten on cards and held up to the camera;

e. Sender is often not visually anonymized within the video, and we see her/his face; sometimes 
he/she only shows his/her face or parts of it (e.g., chin, forehead) and his/her hands;

f. The videos are normally composed in three acts: (I) opening, (II) the message/ content in a narrow sense, and (III) the farewell.

The dramaturgical structure was analysed by studying the structure of the content within the note card stories and can be described as follows:

\section{Opening}

The opening often shows the face of the disclosing individual and the first note card with a written welcoming for the unknown viewers and/or brings up the issue of the video (see Figure 1). Some reveal their name and their grade in school at the very beginning of the video.

From our sampling of 25 videos, the analysis revealed that 16 presenters show their face in the opening part of their video. Another 5 videos show the face afterwards (in the main part) but not in the opening part of the video. The opening starts with silence and/or background music. This part has the function of introducing the presenter to his or her viewers, some revealing their name, and furthermore, starting with the story often after having made clear the focus of their vlog (e.g., confession, secrets).

\section{Main part of the video}

In the main part of the video, the story is being told to the public on YouTube. The card stories analysed in our study deal with different topics, e.g., being a bullying victim, depression, parental divorce, suicidal thoughts; all selected and analysed videos deal with problematic and burdensome issues (see Figure 2). This main part of the video tells the story by showing the central statements (handwritten) on the note cards, which are held to the webcam. In 21 cases, we can see the face of the presenter in the main part, and he/she is therefore visually clearly identifiable.

\section{Final screenshot and farewell}

After having told the story to the unknown public on YouTube, the presenters finalize their video (see Figures 3 and 4). This last part can be seen as a farewell to the viewers. It is quite interesting because this part represents not only the presenter's leave-taking from the unknown audience but also where the producers express their feelings towards the public (e.g., 'I love you'). These emotional messages to the unknown audience can be regarded as an attempt to manipulate the viewers' evaluation of their confession and can be a strategy that uses supplication, self-handicapping, and self-disclosure to influence the perception of both the video and the presenter (see Mummendey, 1995). Others are positively looking ahead in the final part of their video and showing a glimmer of hope at the end. Some only say goodbye, with their video finishing gloomily and without any ray of light.

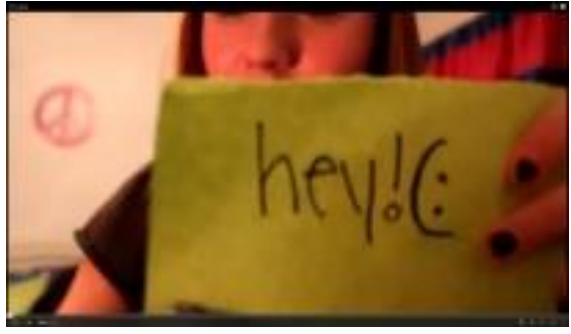

Figure 1. Opening. Source: http://www.youtube.com/wat ch?v=4GIENGcZnS4.

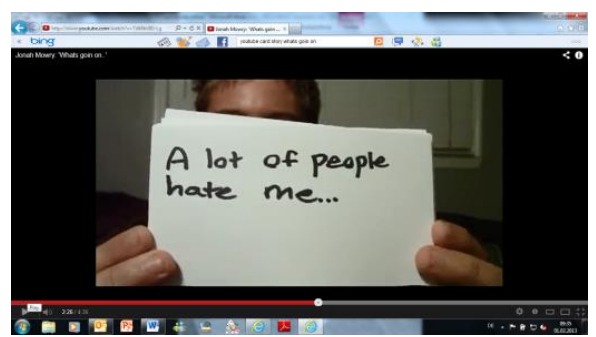

(a)

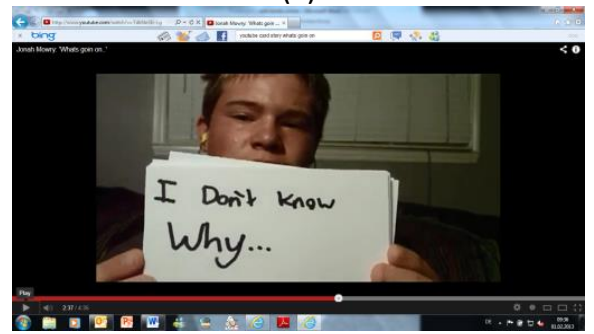

(b)

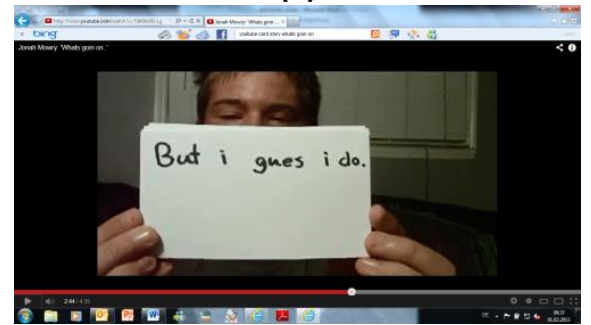

(c)

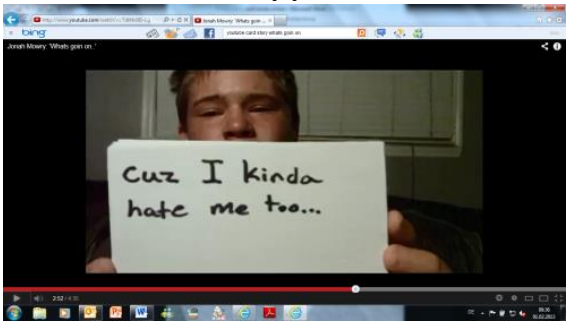

(d)

Figure $2(a-d)$. Main part of the video. Source: http://www.youtube.com/watch?v=TdkNn3Ei-Lg.

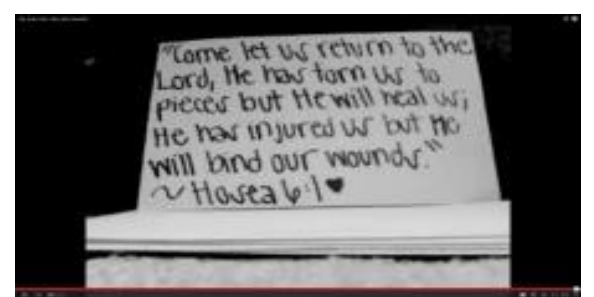

Figure 3. Farewell. Source: https://www.youtube.com/ watch?v=MZbJOVdZstY. 


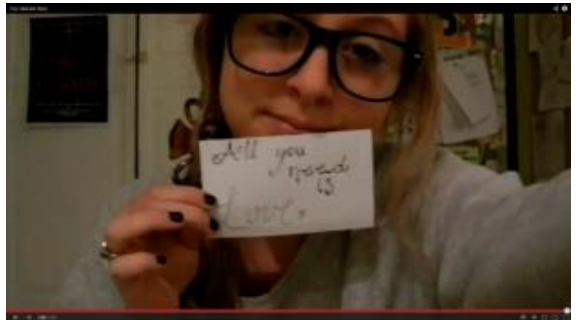

Figure 4. Final screenshot. Source: http://www.youtube. com/watch?v=gC18_43abYE.

\subsection{Topics Dealt with in (Note) Card Stories}

Card stories on YouTube deal with very specific topics. Regarding our sample of 25 videos, the content analysis revealed the following topics: depression, suicidal thoughts, death of a parent or beloved ones, mobbing, self-injury, eating disorders, divorce of parents, bi/transsexualism, cancer, alcoholism, panic attacks, rape, shyness, fears, religion, and loneliness.

Most videos dealt with more than one topic, and depression was the subject most often negotiated.

When we assume that videos with self-referential content can be seen as a specific online genre (Misoch, 2013), we can deduce that note card stories are a subgenre of these self-presentational videos. The frame for these audio-visual self-presentations is quite wide and covers very different forms of videos that deal with oneself-in contrast, the frame for note card stories is very narrow and enhances a strict and specified form of disclosing self-presentation. These presentations are confessions to a dispersed (Maletzke, 1963) and unknown public on YouTube.

\subsection{Card Stories and the Role of Visual Anonymity}

The analysis of our sample showed that most of the presenters of note card stories used a pseudonym in publishing their story: 23 presenters used a name that is explicitly identifiable as a pseudonym and only 2 used a name that could to be the presenter's real name. This finding allows the conclusion that although anonymity seems to be important to the presenter online, a user must have a username to register on YouTube and to open a channel.

Regarding visual anonymity, the analysis of the sample showed a very clear trend towards not staying visually anonymous: About 21 of the publishers of a card-story showed their face within their video and were therefore completely identifiable on a visual level. Only facial parts (e.g., chin, forehead) were shown by 2 presenters (e.g., chin), and only 2 remained totally anonymous within this condition (because their story only consisted of note cards without showing hands or parts of their faces).

This finding is interesting because it contradicts the previous research on this topic, which stated that peo- ple tend to disclose more online when they are (visualIy) anonymous (Joinson, 2001): 'under the protective cloak of anonymity users can express the way they truly feel and think' (McKenna \& Bargh, 2000). This assumption seems to be only partially true for there are several empirical findings that indicate that visual anonymity is not crucial for online self-disclosure (for summary see Misoch, 2014). Characteristics of the media, directionality and synchronicity must be taken into account for this process. These findings of increasing willingness to disclose information indicates that private self-awareness is also heightened in unidirectional situations when communication is not reciprocal. This fact might lead to a higher level of voluntary selfdisclosure.

\subsection{Writing Instead of Telling}

The most important fact concerning this new frame is the obvious one that the presenters do not confess their story verbally (spoken) but in a written manner: the core elements of their story are written (handwritten) on cards, which are then read by the viewer of the video. The auditory channel is therefore not used to speak to the viewers; this channel is solely used for background music, which underlines the video's emotional message.

Regarding letters, Foucault writes: 'to write is thus to "show oneself", to project oneself into view, to make one's own face appear in the other's presence' (Foucault, 1997). This is always the case concerning card stories on YouTube because the presenters write and present their inner feelings to the audience. But the difference consists therein that the written online confession on YouTube is not written to a certain person, and is not part of any communicational exchange. When a letter can be interpreted as '[...] a gaze that one focuses on the addressee (through the missive he receives, he feels looked at) and a way of offering oneself to his gaze by what one tells him about oneself' (Foucault, 1997), the online confessions on YouTube are unilateral, and are only offering the presenter the viewer's view and not vice versa.

As previous studies have shown, disclosing information has positive psychic and physical (immunologic) effects on traumatized individuals (e.g., Pennebaker, 1989; Pennebaker \& O'Heeron, 1984). Moreover, studies have shown that there is a significant difference between verbal and written self-disclosures: When talking about trauma-even if they only talk to a tape recorder-most people are intensely and emotionally involved (score 5.3 of 7 ; and 7 indicates extremely upsetting). This level of unsettlement is significantly lower when disclosing information by writing a text about the traumatic experience (score 2.3 of 7 ; see Pennebaker, 1989). The data shows that the emotional state differs with respect to the modus of disclosure: 
verbal self-disclosure is more upsetting, and therefore leads to more emotional outbursts (like involuntarily crying; Pennebaker, 1989) than written disclosures. To write instead of to tell means having more control over both one's own feelings as well as the disclosed content for the disclosing individual. This is also the case when producing a video. Although videos can be edited and cut before uploading them, the inner distance from one's feelings is significantly higher when writing about the burdening incidences compared to talking about them. This applies even more if the written confessions consist of brief statements in note form: to mention only the most important keywords and events offers a greater distance to the inner feelings than when talking about them in detail (e.g., Pennebaker, 1989).

\section{Discussion}

The so-called (note) card stories constitute a new frame for self-disclosing behaviour by using audiovisual channels online. This frame is a combination of old and new media: it uses strategies of traditional offline communication-sheets of paper or note cards with handwritten messages on it-and combines these messages, which the user holds up to the camera, with a multimedia feature-a webcam - to produce a digital video to be published online. This new frame for selfdisclosure, which entails showing instead of telling one's story, seems to occur more and more often online, and is used for confessions and disclosures. The topics that are confessed by this kind of vlogs are mostly about psychological problems that are imbedded in our society: depression, deaths in the family, suicidal thoughts, mobbing, eating disorders, self-injury, bi/transsexualism, cancer, alcoholism, panic attacks, rape, shyness, fears, religion, divorce of parents, and loneliness. Often several of these topics are addressed within the same video.

The most striking point to this new frame of selfdisclosure on the Internet is that these online confessions take part without visual anonymity. This fact raises the question, which factors are of decisive importance for self-disclosing behaviour online, whether visual anonymity is not essential.

\subsection{Characteristics Related to the Medium and/or Setting which Enhance Self-Disclosure Online}

1. Unidirectionality: video disclosures are unidirectional and asynchronous, and are presented to an unknown mass audience. Therefore, these disclosures have particular characteristics. They are not developing from a superficial level to a more and more intimate level as stated in the Social Penetration Theory (Altman \& Taylor, 1973), and they cannot be interpreted as examples of privacy regulation, according to the Com- munication Privacy Management theory (CPM) (Petronio, 2002), which takes place between relational actors. When self-disclosures normally occur in dyadic interactions, where people speak and interact with each other, they need to make decisions from time to time about what to disclose. These decisions emerge within the interaction and can therefore be changed. Under such 'normal' circumstances, the situation is reciprocal-with the exception of a therapeutic setting or a religious confession. When we regard selfdisclosures on YouTube, they are not integrated in any interaction per se; they are videos that can be watched by others, commented upon, or rated and can be responded to in the form of a video response (for example the following video response: https://www.youtu be.com/watch?v=DfUB55s41_Y, accessed on 24 November 2012). They exist independently from other interaction and communication, and therefore the user decides before producing and uploading his/her video what content he/she wants to disclose and whether to upload or not. This is also the case in other similar settings as weblogs (blogs), often characterized by voluntary self-disclosure (Bortree, 2005; Lee, Im \& Taylor, 2008; Viegas, 2005; Ko \& Kuo, 2009) as well as personal homepages (Misoch, 2007; Stern, 2002) or other self-related media products online (Misoch, 2013; Misoch, 2014). These communicational situations are characterized through asynchronicity and unidirectionality, and it seems that those factors might enhance self-disclosure: 'some people may even experience asynchronous communication as "running away" after posting a message that is personal, emotional, or hostile' (Suler, 2004). This might be explained through the reduced salience of the other social actors within asynchronous settings, and the therefore heightened private self-awareness when the user sits (physically isolated) alone in front of his/her screen. Unidirectionality and asynchronicity seem to enhance processes of self-disclosure (Misoch, 2014) as research revealed concerning unidirectional services for selfpresentation, in particular blogs, personal homepages or videos.

2. Enhanced private self-awareness: the unidirectional situation of asynchronous computer mediated communication leads to a heightening of private selfawareness (see in detail in Section 2.1.2, point 3). In this condition, users are focused intensely on their inner feelings, their own norms and needs and less on social standards or norms of social desirability. This condition can lead to an intensified willingness to disclose information online as, for example, verified for note card stories.

3. Social presence: social presence can be defined as the degree of the salience of other persons in social interactions. Regarding CMC, it was assumed that online communication (textual exchange) has a low 
sense of presence and therefore a low awareness of the social others. This condition was linked to an increased willingness to disclose (because of the heightened private self-awareness). Looking at the phenomenon of video confessions on YouTube, it can thus be stated that the condition of producing and uploading a video on YouTube is a situation with low social presence (asynchronous, no direct feedback) even if the result of this process (the video itself) is of high social presence (channel variety).

4. Stage acting: unidirectional situations on the Internet, which are used for purposes of selfpresentation, can be described through the concept of 'stage acting'. Self-disclosing videos belong to this category of medial self-presentations. Stage acting (Lennox, 1987) is, as the term implies, unidirectional, and other people are, first of all, a passive audience; only in a second step, might others become social interactants. When social (inter-)acting is dependent on reactions from others, stage acting, in contrast, is 'noncontingent upon that feedback and instead depends on predetermined scripts for direction' (Lennox, 1987). This script is the dramaturgical pattern of how users want to present or disclose their information online. This might be realized by telling their own story to the camera, or by writing or showing pictures that illustrate this story, or by writing their sorrows on note cards and presenting them to the camera. This acting is self-centred, and therefore characterized by a heightened self-awareness and self-reflexion because the main goal is to tell others about oneself. This can be realized by hosting a private homepage, writing a blog, posting within a forum, or producing a video as, for example, a note card story about oneself.

\subsection{Characteristics of the Frame of Note Card Stories which Enhance Self-Disclosures}

1. Writing: the modus of writing brief statements on note cards about one's fears and inner feelings instead of talking about them in detail in front of the camera helps the presenter gain a greater inner distance and control over those feelings while confessing. This very special frame might also be appealing and it might be attractive to use the frame of a 'note card story' for the confession of feelings online. To confess within this special frame (and to adhere to the rules) could be an attempt to keep the viewers' attention because this frame might attract more attention by the intertwined structure of visual and textual cues than a video consisting of habitual orality.

2. Acting within the frame: producing and uploading a note card story on YouTube can be the acting within a special frame. This frame is provided by the medium and socially constructed by their viewers, who accept this frame as appropriate for self-disclosing.
When the user transforms his/her feelings to this media frame and confesses his/her sufferings on YouTube by producing a note card story, he/she is acting within this frame.

3. Personal motives: regarding the personal motives, which might lead users to produce and upload a confessional video online, we can only rely on presumptions, since these motives were not part of our exploratory study. Nevertheless, these motives will be mentioned here as concluding hypotheses that need further consideration and should be part of further research in the field of self-disclosing behaviour online.

4. Trust: to confess inner feelings in a nonanonymous way can be a strategy to create trust: ' $\mathrm{k}$ ]nowing a speaker's identity is necessary to better evaluate the truthfulness of the assertions' (Barnes, 1999). Therefore, showing one's identity within online confessions might be a strategy to be more credible online and to be evaluated as authentic by the viewers.

5. Seeking for contact: studies concerning blogs revealed that central motives for blogging are purposes of self-presentation, to express one's feelings (e.g., depression), and to find social contact. One study about blogs showed that the more information the blogger disclosed, the more social capital (Bourdieu, 2002) he/she gained (Ko \& Kuo, 2009). If we transfer these findings to card stories on YouTube, these confessional videos could have the same goal. Showing one's inner feelings and sufferings can therefore be interpreted against the background of the search for contact, perhaps especially to find contact with others who have the same experiences.

6. To regain control: note card videos tell stories about personal experiences of complete loss of control, like being bullied, raped or abused. To produce a video about this experience and to confess this to the audience can be an attempt to cope with this experience and to regain control. Similar to the project "Unbreakable", which aims to increase the awareness to sexual assault and where survivors of sexual assaults hold posters with quotes from their attackers to the camera (http://projectunbreakable.tumblr.com/) ${ }^{1}$.

This study clearly shows that a particular frame for asynchronous, audio-visual self-disclosures arose on the internet within the last five years. This frame, which can be dated back to Bon Dylan in $1967^{2}$ is in its current form a mixture of old media (handwritten message) and new media (digital video on the internet).

\footnotetext{
1 Thank you to Verena Bläser and Gerrit Fröhlich for this important hint.

2 The first note card story was presented in 1967 in the music video 'Homesick Subterranean Blues' by Bob Dylan, where the handwritten note cards (called 'cue cards') are presented to the camera which contained central parts of the song text. Available from: http://www. youtube.com/watch?v=trosB4pa3vg (thank you to one of my anonymous reviewers for this important hint).
} 
This frame, which can be called 'note card story', is a phenomenon where users publicly reveal their inmost feelings and private traumas to an unknown audience. These stories follow a narrow frame with a clear structure, deal with special topics, and are composed following a three-step dramaturgy. Based on our findings, visual anonymity is not a necessary condition for selfdisclosing behaviour online; rather, the characteristics of the medium/mediated setting-as an asynchronous, unidirectional situation, which enhances private selfawareness and a lows social presence-and of the media frame (written message and an acting within the frame) seem to be decisive for self-disclosing behaviour online.

This study is an exploratory study, and we used qualitative methods as content analysis and visual analyses. This means that the conclusions are limited to our sample and to our methodological approach. But by using a qualitative approach, we were able to conduct an in-depth analysis of the frame of the hitherto unknown frame of note card stories. This paper is the first explanatory analysis of this new frame and thus could be the starting point for future research on this emerging phenomenon.

\section{Conflicts of Interest}

The author declares that there are no conflicts of interest.

\section{References}

Altman, I., \& Taylor, D. (1973). Social penetration: The development of interpersonal relationships. New York, NY: Holt.

Archer, R. L. (1980). Self-disclosure. In D. M. Wegner \& R. R. Vallacher (Eds.). The self in social psychology. New York, NY: Oxford University Press.

Attrill, A. (2012). Theoretical considerations and implications of current online self-disclosure research: Is it the quantity or quality of sharing that counts? Retrieved from https://www.dora.dmu.ac.uk/handle/ 2086/6185

Barbour, R. S. (2001). Checklists for improving rigour in qualitative research: a case of the tail wagging the dog? British Medical Journal, 2001(322), 1115-1117.

Barnes, S. B. (1999). Ethical issues for a virtual self. In S. J. Drucker \& G. Gumpert (Eds.). Real law @ virtual space. Cresskill, NJ: Hampton.

Bateson, G. (2006). A theory of play and fantasy. In K. Salen \& E. Zimmerman (Eds.). The game design reader: $A$ rules of play anthology. Cambridge, MA: MIT Press.

Bateson, G. (1973). Steps to an ecology of mind. London: Granada Publication.

Berg, J. H., \& Archer, R. L. (1983). The disclosure-liking relationship. Human Communication Research, 10(2), 269-281.
Berger, C. R., \& Calabrese, R. J. (1975). Some explorations in initial interaction and beyond: Toward a developmental theory of interpersonal communication. Human Communication Theory, 1, 99-112.

Biocca, F., Harms, C., \& Burgoon, J. K. (2003). Toward a more robust theory and measure of social presence: Review and suggested criteria. Presence: Teleoperators and virtual environments, 12(5), 456480.

Bortree, D. S. (2005). Presentation of self on the web: An ethnographic study of teenage girls' weblogs. Education, Communication \& Information, 5(1), 25-39.

Bourdieu, P. (2002). The forms of capital. In N. Woolsey Biggart (Ed.). Readings in economic sociology. Oxford: Blackwell.

Burgess, J. E., \& Green, J. B. (2009). YouTube: Online video and participatory culture. Cambridge, MA: Polity Press.

Cha, M., Kwak, H., Rodriguez, P., Ahn, Y. Y., Tube, M. S. I., \& Tube, Y. (2007). Everybody tubes: Analyzing the world's largest user generated content video system. Paper presented at the 7th ACM SIGCOMM Conference on Internet Measurement, San Diego, CA, USA, 24-26 October 2007.

Chaikin, A. L., \& Derlega, V. J. (1974). Variables affecting the appropriateness of self-disclosure. Journal of Consulting and Clinical Psychology, 42(4), 588593.

Cozby, P. C. (1973). Self-disclosure: A literature review. Psychological Bulletin, 79(2), 73-91.

Derlega, V. J., Metts, S., Petronio, S., \& Margulis, S. T. (1993). Self-disclosure. Newbury Park, CA: Sage.

Duval, S., \& Wicklund, R. A. (1972). A theory of objective self awareness. New York/London: Academic Press.

Entman, R. M. (1993). Framing: Toward clarification of a fractured paradigm. Journal of Communication, 43(4), 51-58

Fenigstein, A., Scheier, M. F., \& Buss, A. H. (1975). Public and private self consciousness: Assessment and theory. Journal of Consulting and Clinical Psychology, 43(4), 522-527.

Fiske, S. T., \& Taylor, S. E. (1991). Social Cognition (2nd ed.). New York, NY: McGraw-Hill Book Company.

Foucault M. (1997). Self writing. In P. Rabinow (Ed.), Ethics: Subjectivity and truth. Essential works of Foucault 1954-1984 (pp. 207-222). London: Penguin.

Goffman, E. (1974). Frame analysis: An essay on the organization of experience. New York, NY: Harper.

Google Blogspot (n.d.). Retrieved from http://google blog.blogspot.de

Griffith, M., \& Papacharissi, Z. (2010). Looking for you: An analysis of video blogs. First Monday, 15, 1-4.

Haridakis, P., \& Hanson, G. (2009). Social interaction and co-viewing with YouTube: Blending mass communication reception and social connection. Jour- 
nal of Broadcasting \& Electronic Media, 53(2), 317335.

Heeter, C. (1992). Being There: The subjective experience of presence. Presence, 1, 262-271.

Joinson, A. N. (2001). Self-disclosure in computermediated communication: The role of selfawareness and visual anonymity. European Journal of Social Psychology, 31, 177-192.

Joinson, A. N. (1999). Social desirability, anonymity, and Internet-based questionnaires. Behavior Research Methods, Instruments \& Computers, 31(3), 433-438.

Jourard, S. M. (1959). Self-disclosure and othercathexis. Journal of Abnormal and Social Psychology, 59(3), 428-431

Jourard, S. M., \& Landsman, M. J. (1960). Cognition, cathexis, and the 'dyadic effect' in men's selfdisclosing behavior. Merrill-Palmer Quarterly of Behavior and Development, 6(3), 178-186.

Jourard, S. M., \& Resnick, J. L. (1970). Some effects of self-disclosure among college women. Journal of Humanistic Psychology, 10(1), 84-93.

Jourard, S. M., \& Richman, P. (1963). Factors in the selfdisclosure inputs of college students. Merrill-Palmer Quarterly of Behavior and Development, 9(2), 141148.

Kiesler, S., Siegel, J., \& McGuire, T. W. (1984). Social psychological aspects of computer-mediated communication. American Psychologist, 39, 1123-1134.

Kleinke, C. L., \& Kahn, M. L. (1980). Perceptions of selfdisclosers: Effects of sex and physical attractiveness. Journal of Personality, 48, 190-205.

Ko, H. C., \& Kuo, F. Y. (2009). Can blogging enhance subjective well-being through self-disclosure. $C y$ berPsychology \& Behavior, 12(1), 75-79.

Kruitbosch G, \& Nack F. (2008). Broadcast yourself on YouTube-Really? Retrieved from: http://staff.sci ence.uva.nl/ nack/papers/hcc02s-kruitbosch.pdf.

Lange, P. G. (2007). Publicly private and privately public: Social networking on YouTube. Journal of Computer-Mediated Communication, 13(1), 361-380.

Lee, D. H., Im, S., \& Taylor, C. R. (2008). Voluntary selfdisclosure of information on the Internet: A multimethod study of the motivations and consequences of disclosing information on blogs. Psychological Marketing, 25, 692-710.

Lennox, R. (1987). Use of the dramaturgical metaphor in the measurement of self-monitoring. Social Behavior and Personality, 15(1), 113-114.

Lindgren, S. (2012). Collective coping through networked narratives: YouTube responses to the Virginia Tech shooting. Studies in Media and Communications, 2012(7), 279-298.

Maletzke, G. (1963). Psychologie der Massenkommunikation. Hamburg: Verlag Hans Bredow Institut.

Matheson, K. (1992). Women and computer technolo- gy. In M. Lea (Ed.). The social contexts of computermediated communication. London: Harvester Wheatsheaf.

Matheson, K., \& Zanna, M. P. (1988). The impact of computer-mediated communication on selfawareness. Computers in Human Behavior, 4(3), 221-233.

Mayring, P. (2010). Qualitative Inhaltsanalyse. Weinheim/ Basel: VS Verlag für Sozialwissenschaften.

McKenna, K. Y. A., \& Bargh, J. A. (2000). Plan 9 from cyberspace: The implications of the Internet for personality and social psychology. Personality and Social Psychology Review, 4(1), 57-75.

Misoch, S. (2007). Die eigene Homepage als Medium adoleszenter Identitätsarbeit. In L. Mikos, D. Hoffmann, \& R. Winter (Eds.). MediennutzungIdentität-Identifikationen (pp. 163-182). Weinheim/München: Juventa.

Misoch, S. (2014). Self-disclosure online: New research results and theoretical modelling. Manuscript submitted for publication.

Misoch, S. (2013). Sind visuelle Selbstoffenbarungen im Netz immer authentisch? In M. Emmer, \& I. Stapf (Eds.). Authentizität in der computervermittelten Kommunikation (pp. 136-154). Weinheim: Beltz Juventa.

Misoch, S. (2012). Visualization of the hidden: The visual communication of self disclosure behaviour in YouTube videos. In I. Zeybek, \& D. Yengin (Eds.). VISUALIST Proceeding Book (pp. 253-260). Istanbul: Istanbul Kültür Üniversitesi.

Mummendey, H. D. (1995). Psychologie der Selbstdarstellung (2nd ed.). Göttingen: Hogrefe.

Pearce, W. B., \& Sharp, S. M. (1973). Self-disclosing communication. Journal of Communication, 23(4), 409-425.

Pennebaker, J. W. (1989). Confession, inhibition, and disease. In L. Berkowitz (Ed.). Advances in experimental social psychology (pp. 211-244). New York: Academic.

Pennebaker, J. W., \& O' Heeron, R. C. (1984). Confiding in others and illness rate among spouses of suicide and accidental death victims. Journal of Abnormal Psychology, 93(4), 473-476.

Petronio, S. (2002). Boundaries of privacy: Dialectics of disclosure. Albany, NY: SUNY Press.

Scheier, M. F. (1976). Self-awareness, self-consciousness, and angry aggression. Journal of Personality, 44(4), 627-644.

Short, J., Williams, E., \& Christie, B. (1976). The social psychology of telecommunications. New York/ London: Wiley.

Stern, S. R. (2002). Virtually speaking: Girls' selfdisclosure on the WWW. Women's Studies in Communication, 25, 223-253.

Suler, J. (2004). The online disinhibition effect. $C y$ berPsychology \& Behavior, 7(3), 321-326. 
Viegas, F. B. (2005). Bloggers' expectations of privacy and accountability: An initial survey. Journal of Computer-Mediated Communication, 10(3). Retrieved from http://jcmc.indiana.edu/vol10/issue3/ viegas.html

Vondracek, F. W., \& Marshall, M. J. (1971). Selfdisclosure and interpersonal trust: An exploratory study. Psychological Reports, 28(1), 235-240.

Weisband, S., \& Kiesler, S. (1996). Self disclosure on computer forms: Meta-analysis and implications. Paper presented at the conference on Human Factors in Computing Systems, April. Retrieved from http://www.sigchi.org/chi96/proceedings/papers/ Weisband/sw_txt.htm.

Wheeless, L. R., \& Grotz, J. (1977). The Measurement of trust and its relationship to self-disclosure. $\mathrm{Hu}$ man Communication Research, 3, 250-257.

\section{About the Author}

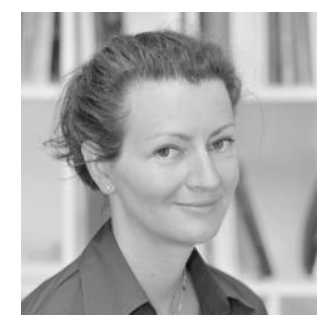

Dr. Sabina Misoch

Sabina Misoch is Head of the Institute for Qualitative Research, in Lucerne (Switzerland), and Senior Researcher at the University of Lucerne. From 2010-2013 she was Professor for Media and Communication Studies at the University of Mannheim (Germany) and terminated this position due to family reasons. She reached her PhD at the University of Karlsruhe (Germany) in 2004 with an empirical study about self-presentations on personal homepages. The focus of her research lies in the field of ICT, in special, computer mediated communication. 